\title{
The Status of Using English at Work by Vietnamese Students after Graduating from University
}

\author{
Huynh Tan Hoi
}

Department of Language, FPT University, Ho Chi Minh city, Vietnam

Received July 14, 2020; Revised August 22, 2020; Accepted September 17, 2020

\section{Cite This Paper in the following Citation Styles}

(a): [1] Huynh Tan Hoi , "The Status of Using English at Work by Vietnamese Students after Graduating from University," Universal Journal of Educational Research, Vol. 8, No. 11, pp. 5318 - 5321, 2020. DOI: 10.13189/ujer.2020.081133.

(b): Huynh Tan Hoi (2020). The Status of Using English at Work by Vietnamese Students after Graduating from University. Universal Journal of Educational Research, 8(11), 5318 - 5321. DOI: 10.13189/ujer.2020.081133.

Copyright $\bigcirc 2020$ by authors, all rights reserved. Authors agree that this article remains permanently open access under the terms of the Creative Commons Attribution License 4.0 International License

\begin{abstract}
In the globalization trend today, for many countries foreign languages are becoming more and more crucial. In Vietnam, English is a compulsory subject at school and it is also an official language commonly used to communicate with foreigners. Having good English benefits employees at work, especially at foreign companies, and accelerates the country in social and economic development. It clearly shows the roles in most aspects of life from construction to health, education, economics and politics - defense. Nevertheless, as it is not the second language, there are still many people who do not seriously take it into consideration to concern it except those who really need the language as a requirement from their jobs. Significantly, for students, studying English when they are at school does not interest them as they are not clearly and practically shown the reasons why they should learn it. Besides, one worth paying attention to is the loss of basic English knowledge of Vietnamese students and it needs to be taken into consideration. In order to apply for better jobs or get more success in life, we need to have the ability to use English well. This paper was completed with documents in both Vietnamese and English and other sources. The article is also based on surveys conducted by students who have graduated from university in Ho Chi Minh City, Vietnam.
\end{abstract}

Keywords English, Difficulty, Future, Job, Student

\section{Introduction}

\subsection{Background}

Vietnam provides abundant human resources, high quality labor, and great natural resources. This is an ideal destination for a lot of foreign investors who expect to achieve breakthroughs in their business as well as their profits in the near future. But in this country, there are still many limitations and challenges that they have to pay attention to and solve immediately if they wish to win larger markets [1].

One of the most pressing constraints is that the supply of high quality intellectual labor able to work in large corporations is still insufficient to meet the needs of multinational companies. The main reason for this shortage is that the majority of human resources are not good at English. Especially in the field of economics, that an employee increases sales to have a good salary is not enough, but it is necessary that they need to use English well for discussing and giving ideas as well as contributions to other people in the company [2].

Therefore, a graduate with a high English language proficiency will have more career opportunities.

\subsection{The Importance of English}

According to the Vietnam General Statistics Office in 2018, the number of jobless people in the first year quarter was 1.1 million. There are many reasons for such a large number and the lack of English communication skills at 
work is also a profound cause that makes individuals unable to choose a good job. Therefore, students need to understand the root of the problem and find solutions for the problem before university or college graduation to have an advantage in the application and in their career [3].

What interferes with students' English learning is the limitation of vocabulary. That students take a long time to look up new words might lead to the failure to quickly capture the communicated information. Besides, pronunciation is also a barrier that students often face. Although Vietnamese and English use roughly the same alphabets, the pronunciation of each syllable is very different. Not only that, the change in teaching methodology (mainly traditional method) by teachers also makes it difficult for students to follow and use [4].

In addition to cultivating their professional working skills, students should exchange experience in using fluent English before working at companies. It can be said that English is a sufficient condition for businesses to recruit an employee into their company. And of course, candidates who can master this language will be given a higher priority.

Today, Vietnam's economy is gradually transforming into a market economy, where foreign investors have opportunities and freedom to participate in the activities of investment and economic development. The presence of more and more multinational companies confirming their position, especially in the field of economics, creates a great deal of opportunities for English proficient students [5].

The demand for English fluent human resources from businesses is increasing sharply day by day. With the ability to use English fluently, a salesperson will have a good salary and a good position. Jobs such as project managers, engineers are always ready to welcome staff with good English skills.

\subsection{Literature Review}

According to the dictionary of the University of South Queensland (2016), English competency is defined as "the ability of learners to use English to transmit information through forms of speaking or writing during their study" [6].

There are many reasons for students to assess that speaking skill is toughest as their vocabulary is low, the ability to use grammar is not flexible, the training is not focused and regularly. Students think speaking skill is the toughest to master because their vocabulary is low, their ability to use grammar is limited. In order to realize the improvement in learning progress, it takes students long time of hard practice and patience [5].

Teaching foreign languages in recent years at universities and colleges in the direction of communication has been the main method that is widely applied to all classes of the national program from the Vietnam Ministry of Education and Training. Training communication skill is considered as a basic goal in the process of teaching and learning English, in which all four skills of listening, speaking, reading, and writing are specially focused for all lectures in the faculty of foreign languages [3]. Listening comprehension is no longer a passive language skill, but it has become an active skill the learners play an active role as participants in listening, processing information in order that they are able to eventually respond to the information.

Today, in sentences for diverse and international audience such as instruction boards, public guides, the use of more than one language is necessary. Signboards, bilingual or even multilingual guides are becoming more and more popular. As an international language, English is always chosen as the first used foreign language on the signs and instructions. In tourism, a multilingual and multicultural specialized business, languages in general and foreign languages in particular play an important role and have a special potential. It is not only a tool transmitting culture, but language is also a bridge between tourists and local people and local tourism businesses, and an effective means to attract tourists. However, the use of English as well as other foreign languages in tourist signs is less concerned in order to maximize the effectiveness of the signs [4].

\section{Materials and Methods}

This paper was supported by the completion of the test form of 29 young people aged 20 to 25 years including students at universities and young people working in different companies in Ho Chi Minh City.

These participants were chosen because they are people who are in the process of seeking to secure jobs in various companies.. Therefore, the objectivity and reality of the data collected will be clearer [7].

Thanks to the support of the respondents who are presently studying at FPT University, Vietnam, a survey was conducted online at https://surveynuts.com. Using the form of direct interview and method of completing questionnaires, the role of English has clearly affirmed. The paper was also based on the collected data and knowledge of related journals and it agrees with these results.

\section{Results and Discussion}

\subsection{Difficulties in Learning English}

The fact that Vietnamese students start learning English in their early age has both advantages and disadvantages. On the positive side, it cannot be denied that children can learn English better than adults as they have a lot of more time and they seem to interact and react with the language 
naturally. However, it is also the reason why they lose their foundation. Many students know only what the word means but do not know how to put it into sentences that are grammatically correct [8].

Besides, with the data collected, we realized that a number of Vietnamese find it hard to write the language.

There are many reasons that make students evaluate that writing skill is the hardest such as their vocabulary is low, the ability to use grammar is not flexible and the training is not regular. [6] One more thing is that students have studied the same grammar structures from secondary school to high school, however, they do not many chances to apply in real life and as a result, they might forget what they have learnt before (Figure 1).

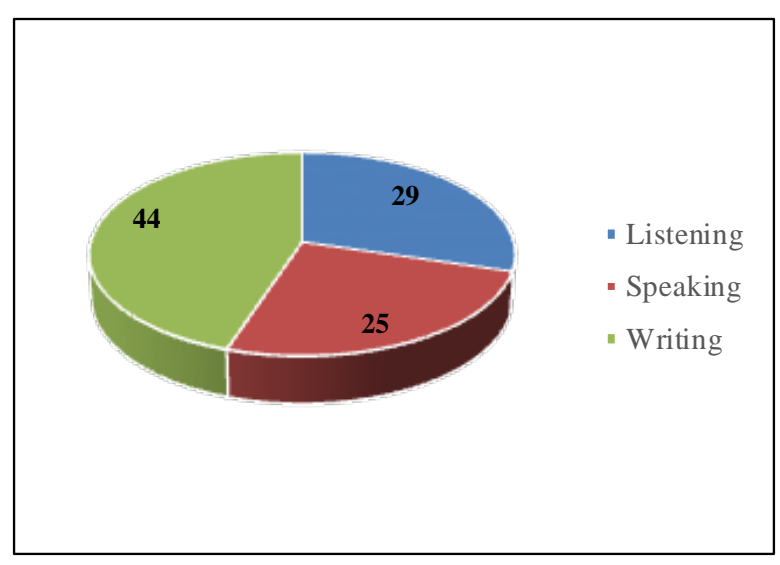

Figure 1. Skills difficult to get approach in English

According to the survey above, 44 people chose writing as the hardest skill. The participants indicated that writing is hard partly due to the fact that they didn't have a grasp of enough grammar and vocabulary.

The third difficulty in using English is communication skill. This is derived from the shyness of each individual. Everyone thinks that the grammar they are using is wrong, then it makes the listeners not able to understand. This leads to the low frequency of using English in everyday life. Low self-esteem in communication is an obstacle when learning to communicate in English as well [9]. Psychology is a big barrier, directly affecting the process of improving English communication. One of the most important things is the learners should be more open and think positively in the study, then their communication in English will be improved.

Some learners think in their mother tongue first and then convert the ideas into the language much more easier. It causes the lack of natural reflex when speaking. It is even worse that in difficult situations when the learners could not find the words for making sentences, they will get worried and lose confidence to continue communicating in English.

For that reason, there were up to 12 votes "Not good at English" for the question "Reason for not using English at work." As the data show, we could recognize that there are so many jobs that the workers are not required to have good English, so the number of students who do not find it necessary to learn English well and consider it an important subject remains relatively high.

It is a fact that except for international companies in Vietnam where the communicative language is a foreign language such as English, Chinese, Korean, etc.,, the working environment in the others certainly prefers to keep Vietnamese-speaking as the main way of communication. Therefore, a number of Vietnamese students believe that they can still find jobs without English [6].

Therefore, if we expect more people to use foreign languages at work, domestic companies need to cooperate with foreign companies. By so doing, not only are the company's profits increased, but it also helps to improve the quality and ability in terms of using foreign languages (Figure 2).

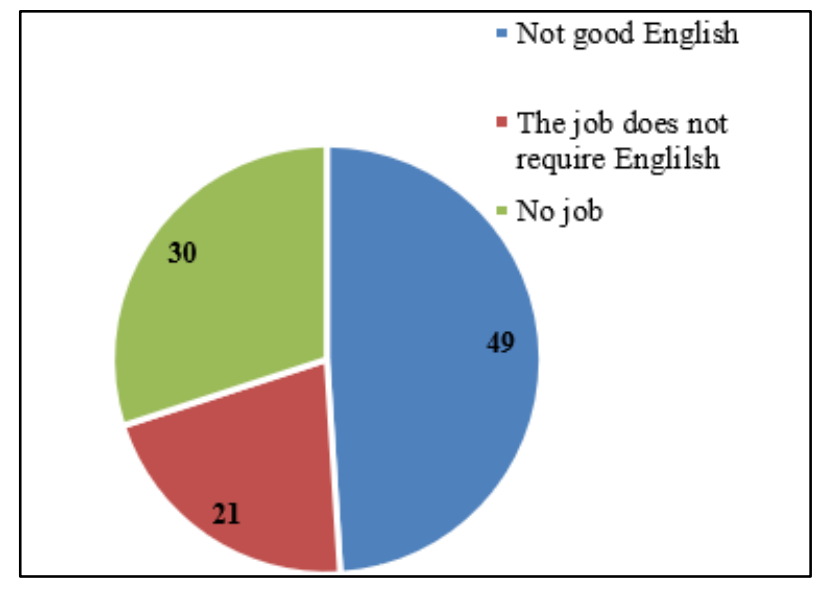

Figure 2. Reasons for not using English at work

\subsection{Solutions for Improving English}

There are a lot of solutions to help students improve their English. This article will mention a few specific suggestions:

For writing, students should read a lot of books and newspapers in various areas so that their vocabulary as well as the amount of knowledge in those fields are updated day by day. They can then practice by writing short texts several times a week. After writing, students should ask friends and teachers to check the works out. The process will benefit students in both social knowledge, writing skill and the relationships with friends surrounding them.

For speaking, English could be practiced through watching movies, listening to music and repeating after the sentences in order to imitate the characters' accents. It is not really necessary to watch all types of movies, making foreign friends with which English language speaking practice could be done is another effective way of improving speaking skills [4].

In case the students have less spare time to study English, they should use their "downtime". In the time gaps like 
sitting on the bus, driving to work, cooking, bathing, students should turn on radio channels like BBC News to listen passively [5]. This kind of listening can help them to learn more about pronunciation, intonation of the native speakers as well as drill the students in their accent. However, we need to know that no matter how good the method is, the students have to learn the language voluntarily to develop themselves.

Develop training and retraining schemes and improve English proficiency for teachers at specialized faculties so that they can teach subjects, especially subjects in the fields of nature, economics, business administration and technology in English [1].

The investment for building English standard English classes with high quality equipment of sound systems, teaching techniques, together with a good environment in communicating in English is also necessary to contribute to turn English into a second language in the academic environment at Vietnam National University, Hanoi. Besides, information technology should be applied to the teaching and learning at the university [8].

\section{Conclusions}

In this globalization trend, foreign languages are considered as the key that can be used to open the door of integration with the outside world. Therefore, each individual needs to learn to gain more necessary knowledge in order to meet tough requirements from employers. However, learning English well is never enough and the applicants also need to learn principles and communicative regulations at work as they are vital criteria in big companies. If these are done well, our career will go further.

\section{Acknowledgements}

I would like to send my warm thanks to my colleagues as well as the financial support of my university.

\section{REFERENCES}

[1] Trang, T. T. T., \& Baldauf Jr, R. B. Demotivation: Understanding resistance to English language learning-the case of Vietnamese students. The journal of Asia TEFL, Vol 4, No 1, 79-105, 2007.

[2] Nguyen, M. H. The curriculum for English language teacher education in Australian and Vietnamese universities. Australian Journal of Teacher Education, Vol.38, No 11, 3, 2013.

[3] BANG, T. C. The motivation of Vietnamese university students to learn English: A study using the expectancy-value model of academic motivation (Doctoral dissertation, The University of Newcastle), 2016.

[4] Phuong, L. N. T., \& Nhu, T. P. Innovation in English language education in Vietnam for ASEAN 2015 Integration: Current issues, challenges, opportunities, investments and solutions. ASEAN Integration and Role of ELT, 104, 2015.

[5] Hoi, H. T. Efficiency of Japanese-Vietnamese Translation Job Thanks to the Use of Technology in the Fourth Industrial Revolution. In Proceedings of the 2019 The 3rd International Conference on Digital Technology in Education, 181-184, 2019.

[6] Nguyen, M. H. The curriculum for English language teacher education in Australian and Vietnamese universities. Australian Journal of Teacher Education, Vol.38, No. 11, 3, 2013.

[7] Birrell, B. Implications of low English standards among overseas students at Australian universities. People and place, Vol.14, No.4, 53, 2006.

[8] Rogerson-Revell, P. Using English for international business: A European case study. English for specific purposes, Vol.26, No.1, 103-120, 2007.

[9] Tran, T. T. Factors affecting teaching and learning English in Vietnamese universities. The Internet journal language, culture and society, Vol.38, No.1, 138-145, 2013. 